\title{
Mutational Analysis of the CTNNB1 and APC Genes in Uterine Endometrioid Carcinoma
}

\author{
Peter W. Schlosshauer, M.D., Edyta C. Pirog, M.D., Ross L. Levine, M.D., Lora Hedrick Ellenson, M.D. \\ Department of Pathology, Joan and Sanford I. Weill Medical College of Cornell University, New York
}

Despite recent studies, the molecular genetic events responsible for the development of uterine endometrioid carcinoma (UEC) remain incompletely characterized. Mutations in the $\beta$-catenin (CTNNB1) gene have been recently reported in a small percentage of UECs and in the endometrioid variant of ovarian carcinoma suggesting that the Wnt signal transduction pathway is involved in the development of female genital tract tumors with endometrioid morphology. The Wnt pathway is a critical pathway in the development of colorectal cancer (CRC) with mutations occurring in the $\beta$-catenin (CTNNB1) or adenomatous polyposis coli $(A P C)$ genes in 10 to $15 \%$ and $85 \%$ of cases, respectively. Because UEC and CRC share other molecular genetic alterations and histologic features and previous studies of UEC have not reported an analysis of the $A P C$ gene, we chose to further elucidate the role of the Wnt pathway in UEC. To this end, we analyzed 32 cases of UEC for mutations of the CTNNB1 and APC genes. Mutations of CTNNB1 were present in six of $32(18 \%)$ cases: four grade 1 carcinomas, one grade 2 , and one grade 3 carcinoma. Five missense mutations were identified, three involving Ser/Thr phosphorylation sites and two adjacent to a Ser phosphorylation site. One case contained a deletion encompassing codons 34 to 37 , which includes a Ser phosphorylation site. No mutations resulting in truncation of the APC protein were found. Our results support a role for the Wnt signaling pathway via mutation of $C T N N B 1$, but not $A P C$, in the development of a subset of UECs.

Copyright $(2000$ by The United States and Canadian Academy of Pathology, Inc.

VOL. 13, NO. 10, P. 1066, 2000 Printed in the U.S.A.

Date of acceptance: May 19, 2000.

This work was partially supported by a College of American Pathologists (CAP) Foundation Scholarship (PWS) and the Mary Kay Ash Charitable Foundation (LHE).

Dr. Schlosshauer and Dr. Pirog contributed equally to the work presented in this manuscript.

Address reprint requests to: Lora Hedrick Ellenson, M.D., New York Weill Cornell Center of New York Presbyterian Hospital, Department of Pathology, 1300 York Avenue, Room Starr 1005, New York, NY 10021; e-mail: lhellens@med.cornell.edu; fax: 212-746-5577.
KEY WORDS: APC, $\beta$-Catenin, Mutations, Uterine endometrioid carcinoma, Wnt.

Mod Pathol 2000;13(10):1066-1071

Endometrial carcinoma is the most common malignancy of the female genital tract in the United States with approximately 37,400 newly diagnosed cases and 6400 deaths expected to occur in 1999 (1). Uterine endometrioid carcinoma (UEC) accounts for $85 \%$ of all cases of endometrial carcinoma. This subtype is associated with classic risk factors (such as obesity, diabetes mellitus, hypertension, nulliparity, unopposed estrogen stimulation), tends to occur in peri- or post-menopausal women (mean age, 59 years) and has a relatively favorable prognosis as compared to other types of endometrial carcinoma (e.g., serous or clear cell carcinoma). Morphologically, UECs usually present as exophytic tumors composed of glands resembling proliferative endometrium. The histologic features overlap with those of colorectal carcinoma (CRC), often making the distinction between the two entities difficult when they present as metastatic disease. Also, UEC and CRC share several molecular genetic characteristics (e.g., mutations in the K-ras and p53 genes and microsatellite instability) in a significant proportion of cases (reviewed in 2, 3). Recent studies have shown that $85 \%$ of CRC harbor a mutation in the adenomatous polyposis coli $(A P C)$ gene, and of the remaining tumors with wild-type $A P C$, approximately $50 \%$ have a mutated $\beta$-catenin gene (CTNNB1) (4). Both the putative oncoprotein $\beta$-catenin and the adenomatous polyposis coli (APC) tumor suppressor protein are elements of the Wnt signaling pathway that have been implicated in embryonic development and carcinogenesis.

Activation of the Wnt pathway leads to a sequence of protein interactions involving a transmembranous receptor of the frizzled family and the cytoplasmic proteins dishevelled, glycogen synthase kinase $3 \beta$ (GSK-3 $\beta$ ), APC, axin and $\beta$-catenin, resulting in stabilization of $\beta$-catenin $(5,6)$. The stabilization leads to a relative increase in $\beta$-catenin levels with subsequent translocation of $\beta$-catenin to the nucleus, where it binds to T-cell factor (TCF)- 
class transcriptional factors and induces expression of TCF-responsive genes (7). Recently, the $c$-myc and cyclin D1 (PRAD-1) genes have been identified as target genes for $\beta$-catenin/Tcf induced transcription $(8,9)$. In non-proliferating cells, the cytosolic level of free $\beta$-catenin is downregulated through interaction with a multiprotein complex consisting of APC, GSK-3 $\beta$, and axin (reviewed in 10, 11, 12) (Fig. 1). APC promotes the phosphorylation of $\beta$-catenin at several Ser/Thr residues encoded in exon 3 , which in turn targets $\beta$-catenin for ubiquitin-dependent degradation. Similarly, alterations of elements in the Wnt signal transduction cascade (e.g., mutations in APC or CTNNB1) may result in $\beta$-catenin stabilization $(4,11)$. APC mutations most commonly occur within the mutation cluster region (MCR) between codons 1286 and 1513 (13) and result in a truncated form of the protein that lacks the ability to promote $\beta$-catenin degradation. Stabilizing mutations of $\beta$-catenin most frequently affect Ser/Thr phosphorylation sites encoded in exon 3.

Unlike in CRC, APC mutations have not been reported in UEC. However, the findings of mutations in CTNNB1 and immunohistochemical overexpression of $\beta$-catenin in a proportion of cases of uterine endometrioid carcinoma $(14,15)$ and in the endometrioid variant of ovarian carcinoma (16) suggest a role for the Wnt signaling pathway in tumors with endometrioid features. To further investigate this hypothesis we analyzed 32 UECs for mutations in the CTNNB1 and APC genes.

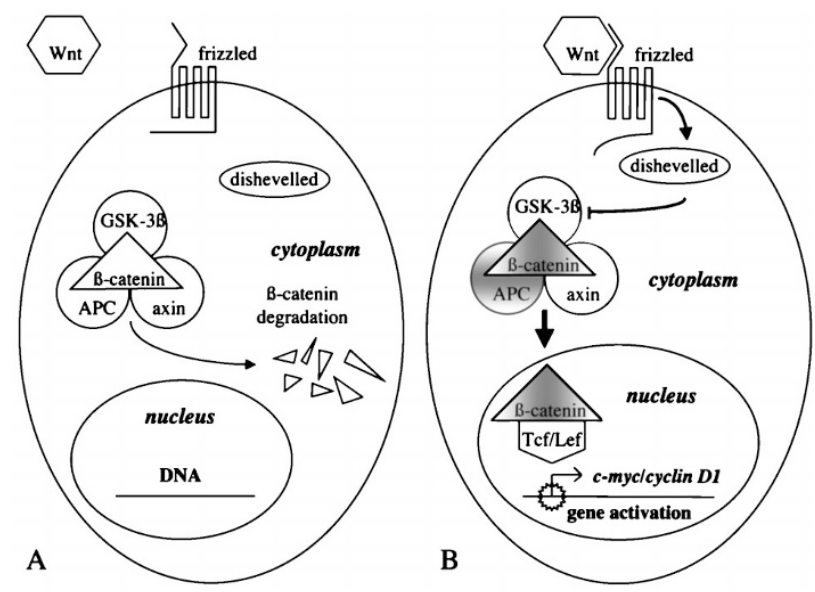

FIGURE 1. A, In the absence of Wnt signaling, $\beta$-catenin is degraded through interaction with a multiprotein complex containing APC, GSK$3 \beta$, and axin. B, Wnt signaling via the receptor frizzled and the cytosolic protein dishevelled leads to inhibition of GSK- $3 \beta$ and thereby suppression of $\beta$-catenin degradation. Similarly, stabilizing mutations of $\beta$-catenin or truncating mutations of APC result in cytosolic accumulation of $\beta$-catenin, its translocation to the nucleus and activation of Tcf responsive genes, such as $c-m y c$ or cyclin D1.

\section{MATERIALS AND METHODS}

\section{Samples}

Thirty-two cases of uterine endometrioid adenocarcinoma, including 12 grade I tumors, 11 grade II, and nine grade III tumors, were collected from the Johns Hopkins University Tissue Bank. Frozen tumor tissue was microdissected to obtain more than $70 \%$ tumor cells. Corresponding normal tissue was microdissected from the same specimens. DNA was isolated and purified by previously described techniques $(17,18)$.

\section{Mutational Analysis of the CTNNB1 Gene}

Sequence analysis of the CTNNB1 gene was performed by polymerase chain reaction (PCR) amplification of a 159-bp fragment of exon 3 (codons 21 to 73), followed by direct cycle sequencing. PCR amplification of genomic DNA was performed as described previously (16) with slight modifications. In brief, the PCR reaction contained $10 \mathrm{~mm}$ Tris- $\mathrm{HCl}$ (pH 9.1), $1.5 \mathrm{~mm} \mathrm{MgCl}_{2}, 75 \mathrm{~mm} \mathrm{KCl}, 0.02 \% \mathrm{NaOH}$, $200 \mu \mathrm{m}$ dNTPs, 6.25 pmol of each primer $\left(240 \mathrm{~F}: 5^{\prime}-\right.$ ATGGAACCAGACAGAAAAGC-3'; 439F: 5'-GCTACTTGTTCTTGAGTGAAG-3'), 1.0 U of Taq polymerase and $40 \mathrm{ng}$ of genomic DNA in a final volume of $25 \mu \mathrm{L}$. Reaction products were treated with exonuclease I and shrimp alkaline phosphatase using a PCR product presequencing kit (Amersham Life Science, Cleveland, $\mathrm{OH}$ ) and sequenced with the Thermo Sequenase sequencing kit (Amersham Life Science) with either one of the primers used for the initial amplification. The sequencing reaction was carried out according to the manufacturer's recommendations: 30 cycles at $95^{\circ} \mathrm{C}$ for 30 seconds, followed by $55^{\circ} \mathrm{C}$ for 30 seconds and $72^{\circ} \mathrm{C}$ for 90 seconds. Aliquots of the PCR products were submitted to electrophoresis on a CastAway sequencing device (Stratagene, La Jolla, CA) using precast 6\% polyacrylamide gels containing $7 \mathrm{~m}$ urea. Gels were exposed to autoradiography film (BioMax, Kodak, Rochester, NY). Mutations were verified by repeating the sequence analysis in both the sense and antisense directions and, when necessary, sequencing cloned products using the Original TA Cloning Kit (Invitrogen Corporation, Carlsbad, CA).

The somatic nature of the mutations was confirmed by analyzing DNA derived from patient matched normal tissue, which showed the wildtype $\beta$-catenin sequence in all cases examined.

\section{Mutational Analysis of the Adenomatous Polyposis Coli Gene}

To screen for truncation mutations of the $A P C$ gene, a protein truncation assay (TNT Coupled Reticulocyte Lysate System; Promega, Madison, WI) 
was used, following the manufacturer's instructions. Genomic DNA was obtained as described above and used to PCR-amplify two overlapping segments of the APC gene, spanning the region from codon 686 to 1693, which includes the mutation cluster region (MCR, codons 1286 to 1513) (13). The following T7-modified sense primers (T7-trans = GGATCCTAATACGACTCACTATAGGGAGACCACCATGG) were used under the conditions described previously (19):

\section{Segment A (Codons 686 to 1217) \\ F 5' -[T7-trans]-ATGCATGTGGAACTTTGTGG-3' R 5'-GAGGATCCATTAGATGAAGGTGTGGACG-3'}

\section{Segment B (Codons 1099 to 1693)}

\section{F 5' -[T7-trans]-TTTCTCCATACAGGTCACGG-3' R 5'-GGAGGATCCTGTAGGAATGGTATCTCG-3'}

The PCR reaction contained $10 \mathrm{~mm}$ Tris- $\mathrm{HCl}, 1.5$ $\mathrm{mm} \mathrm{Mg} \mathrm{Cl}, 75 \mathrm{~mm} \mathrm{KCl}, 0.0325 \% \mathrm{NaOH}, 40 \mathrm{ng}$ of genomic template DNA, 50 pmol of each primer, 2.5 $\mathrm{U}$ Taq polymerase and $200 \mu \mathrm{M}$ dNTPs in a final volume of $50 \mu \mathrm{L}$. Amplification was carried out in 35 cycles of $95^{\circ} \mathrm{C}$ for 60 seconds, $55^{\circ} \mathrm{C}$ for 90 seconds and $70^{\circ} \mathrm{C}$ for 120 seconds; mononucleotides were added to the reaction mix during the first cycle at a temperature of at least $80^{\circ} \mathrm{C}$.

PCR products were purified by phenolchloroform extraction and sodium-perchlorate precipitation. The combined in vitro transcription/ translation based TNT assay was performed using 2 $\mu \mathrm{g}$ of these PCR products and $2 \mu \mathrm{L}\left[{ }^{35} \mathrm{~S}\right]$ methionine $(1000 \mathrm{Ci} / \mathrm{mmol})$ in a $50-\mu \mathrm{L}$ reaction as described by the manufacturer. The reaction product was admixed with protein sample buffer (final concentrations: 60 mu Tris, pH 6.8; $2 \%$ SDS; $10 \%$ glycerol; 0.7 м 2-mercaptoethanol; 0.025\% Bromphenol Blue), and boiled for $5 \mathrm{~min}$. Sample aliquots containing 5 $\mu \mathrm{L}$ of the TNT product were separated by SDSpolyacrylamide gel electrophoresis using 4 to $20 \%$ Tris-HCl gels (Ready Gel, BioRad, Hercules, CA). The protein bands representing the generated APCsegments were visualized by autoradiography (BioMax, Kodak, Rochester, NY). Negative controls without DNA were run in parallel for each reaction.

\section{Protein Extraction and Western Blotting}

Fresh frozen tumor tissue was pulverized on dry ice and suspended in lysis buffer (final concentrations: 20 mu Tris, pH 7.5; 1 mm EDTA; 100 mu NaCl; $1 \%$ Triton-X-100; $0.5 \%$ Deoxycholic acid; $0.1 \%$ Sodium Dodecyl Sulfate; 1 mm EGTA; 1 mM PMSF; 0.5 $\mu \mathrm{g} / \mathrm{mL}$ Leupeptin; $5.0 \mu \mathrm{g} / \mathrm{mL}$ Antipain; $0.7 \mu \mathrm{g} / \mathrm{mL}$ Pepstatin A; $50 \mathrm{~mm}$ NaF; $10 \mathrm{~mm} \beta$-Glycerophosphate; $10 \mathrm{~mm}$ Na-pyrophosphate; $1 \mathrm{~mm}$ Na-Vana- date; $10 \mu \mathrm{M}$ Na-Molybdate). After incubation and centrifugation the supernatant was admixed with Laemmli buffer and submitted to electrophoresis on $10 \%$ polyacrylamide Tris- $\mathrm{HCl}$ gels in a Ready Gel Cell device (BioRad), following the manufacturer's instructions. Proteins were transferred to Immobilon P membrane (Millipore, Bedford, MA) and probed with antibodies directed against c-myc or cyclin D1 proteins (both antibodies from Santa Cruz, CA; both antibodies were used in a 1:200 dilution). Protein bands were visualized with the ECL kit (Amersham, Arlington Heights, IL) and exposure to autoradiography film (BioMax).

\section{RESULTS}

Mutational analysis of the CTNNB1 was performed by sequencing a 159-bp fragment of exon 3 (codons 21 to 73), which encompasses the sequence for multiple GSK- $3 \beta$ phosphorylation sites. CTNNB1 mutations were found in six of $32(18 \%)$ cases. Five missense mutations were identified, three involving Ser/Thr phosphorylation sites and two adjacent to a Ser phosphorylation site at codon 33 (Table 1 and Fig. 2). In one case, a deletion of 12 $\mathrm{bp}$, corresponding to an in-frame loss of codons 34 to 37 , was detected. This includes the Ser 37 phosphorylation site. In all tumors with CTNNB1 mutations, the wild-type sequence was also identified, indicating that only one allele was mutated. Of the six cases with mutations, four were grade 1 carcinomas and, one each, a grade 2 and a grade 3 carcinoma.

A protein truncation assay was used to screen for mutations of the $A P C$ gene between codons 686 and 1693. No mutations resulting in truncation of the APC protein were found (Fig. 3).

Limited amounts of fresh frozen tissue were available from fifteen of the 32 primary tumors in our series, among them four of the six tumors with $\beta$-catenin mutations. Protein extracts of those samples were analyzed for c-myc- and cyclin D1 expression by Western blot, using control samples from tumors matched for histologic features, tumor grade and stage, and patient age. However, no cor-

TABLE 1. Mutations of CTNNB1 in Uterine Endometrioid Carcinoma

\begin{tabular}{|c|c|c|c|c|}
\hline Case & $\begin{array}{l}\text { Tumor } \\
\text { Grade }\end{array}$ & $\begin{array}{l}\text { Mutated } \\
\text { Codon }\end{array}$ & Base Change & $\begin{array}{l}\text { Amino Acid } \\
\text { Substitution }\end{array}$ \\
\hline 1 & 1 & 32 & $\mathrm{GAC} \rightarrow$ & Asp $\rightarrow$ Tyr \\
\hline 2 & 1 & 45 & $\mathrm{TCT} \rightarrow$ & Ser $\rightarrow$ Pro \\
\hline 3 & 1 & 37 & $\mathrm{TCT} \rightarrow$ & Ser $\rightarrow$ Phe \\
\hline 4 & 2 & 32 & $\mathrm{GAC} \rightarrow$ & Asp $\rightarrow$ Tyr \\
\hline 5 & 3 & 41 & $\mathrm{ACC} \rightarrow \quad$ GCC & $\mathrm{Thr} \rightarrow$ Ala \\
\hline 6 & 1 & 34 to37 & 12bpDeletion & $\begin{array}{c}\text { 4aa } \\
\text { Deletion }\end{array}$ \\
\hline
\end{tabular}

bp, base pair; aa, amino acid. 


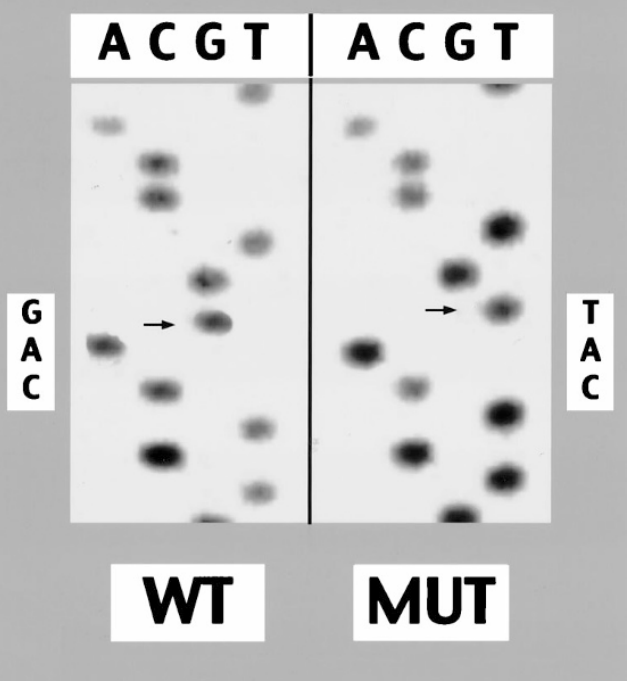

FIGURE 2. DNA sequence from the regulatory domain of the CTNNB1 gene: $\mathrm{G} \rightarrow \mathrm{T}$ substitution at codon 32 (WT, wild type; MUT, case 1 from Table 1 ).

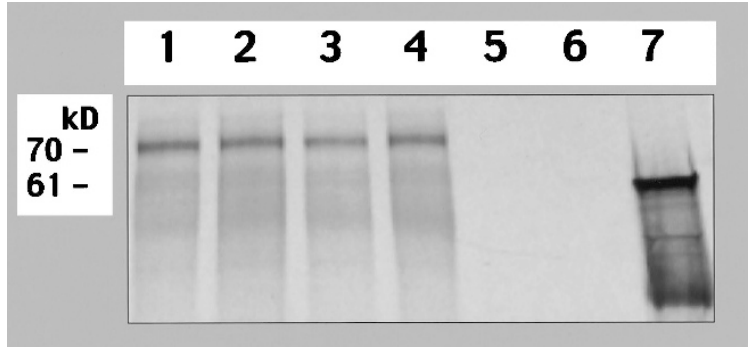

FIGURE 3. Protein truncation assay of APC-segment B. The reaction results in synthesis of a $70 \mathrm{kDa}$ APC protein fragment. Four representative tumor samples (lanes 1-4) are shown. No aberrant proteins are identified. Negative controls (lanes 5-6), run without DNA do not express protein. The positive control (lane 7), run with DNA encoding luciferase, shows the respective protein product of $61 \mathrm{kDa}$.

relation with the $\beta$-catenin mutational status was evident (data not shown).

The mutational status of the Ras oncogene, the p53 and PTEN tumor suppressor genes, the microsatellite instability status, and the $M L H 1$ promoter methylation status of most of the analyzed cases were known as published previously $(18,20,21,22)$. No statistically significant correlation could be established between any of these parameters and the $\beta$-catenin mutational status.

\section{DISCUSSION}

$\beta$-catenin is a multifunctional protein initially identified as part of a complex connecting the cell adhesion molecule E-cadherin to $\alpha$-catenin and the cytoskeleton. Subsequently, it was established as an essential protein in the Wnt signaling pathway. Activation of Wnt signaling, resulting from mutations in either the APC or $\beta$-catenin (CTNNB1) gene, has been implicated in the pathogenesis of colorectal carcinoma (CRC) $(4,23)$, melanoma (24), medulloblastoma (25), prostate (26), gastric (27), and hepatocellular carcinoma $(28,29)$. Recently, mutations in $C T N N B 1$ were also identified in uterine endometrioid carcinoma (UEC) $(14,15)$ and in the endometrioid variant of ovarian carcinoma (16); however, neither study included analyses of the $A P C$ gene.

In this study, we analyzed 32 cases of UEC and identified somatic mutations in the regulatory domain of the $\beta$-catenin gene in six out of 32 tumors (18\%). Mutations similar to those detected in this study have previously been described $(4,14,16,23)$. Our study confirms previous observations that $\beta$-catenin mutations occur in about $15 \%$ of UECs and tend to be more frequent in low-grade, lowstage tumors $(14,15), \beta$-catenin mutations have been reported so far only in UECs, but not in other subtypes of endometrial carcinoma. Preliminary data from our own laboratory confirm that $\beta$-catenin overexpression is present in a subset of UECs, but not uterine serous carcinomas. Thus, molecular analysis suggests that the different morphologic characteristics reflect different underlying genetic alterations. Immunohistochemical studies $(14,15,16)$ showed cytoplasmic and/or nuclear overexpression of $\beta$-catenin in cases with, but also without, $\beta$-catenin mutations. Some authors hypothesize that $\beta$-catenin accumulation in the latter cases may be due to APC-mutations (16). To our knowledge, we report the first study of the mutational status of $A P C$ in UEC; however, no truncating mutations of the $A P C$ gene between codons 686 and 1693 were found. In our analysis, we focused on those regions of the CTNNBI and APC genes that are known to frequently harbor mutations in CRC. It is possible that UEC is predisposed to a different spectrum of mutations in these genes which was not covered by our methods.

$\beta$-catenin has been shown to be a downstream activator of the Wnt signaling pathway by binding Tcf transcription factors. Recently, $c$-myc and cyclin $D 1$ were identified as targets of $\beta$-catenin/Tcfmediated transcriptional activation $(8,9)$. Overexpression of $\beta$-catenin, attributable to either stabilizing mutations of CTNNB1 or truncating mutations of the $A P C$ gene, was shown to upregulate c-myc expression in colon cancer cell lines. This finding provides a plausible explanation for the observed overexpression of c-myc protein in CRC. C-myc overexpression is also found in more than $50 \%$ of endometrial tumors $(30,31,32)$, which may be the result of upregulation of the Wnt signaling pathway. Western blot analysis of selected cases from our series did not reveal a correlation between c-myc expression and $\beta$-catenin mutational status. A possible explanation is that c-myc expression is determined by multiple factors, of 
which $\beta$-catenin is only one. In addition, mutations in CTNNB1 may have a different effect on c-myc in UEC than CRC.

Similarly, we were unable to demonstrate cyclin D1 expression in our tumor samples by Western blot analysis. Immunohistochemical studies had shown increased expression of cyclin D1 in 40 to $56 \%$ of UEC $(33,34)$. Interestingly, cell proliferation after estrogenic stimulation is associated with upregulation of both cyclin D1 and c-myc (35). Conversely, both cyclin D1 and c-myc can mimic estrogen effects on S-phase entry during the cell cycle $(36,37)$. Thus, unopposed estrogen stimulation of the endometrium may be due to upregulation of cyclin D1 and/or c-myc. Since there is no evidence of interaction between the estrogen and Wnt signaling cascades, it its possible that both pathways converge towards a common step that includes upregulation of cyclin D1 and c-myc to promote proliferation.

In summary, we found mutations in the $\beta$-catenin gene in $18 \%$ of UEC. These results support a role for the Wnt signaling pathway, via mutation of CTNNB1 but not $A P C$, in the development of a subset of UEC. Future studies of endometrial precursor lesions (e.g., complex atypical hyperplasia) and cell lines are needed to determine the timing and consequence of such mutations in UEC.

\section{REFERENCES}

1. Bristow RE. Endometrial cancer. Curr Opin Oncol 1999;11: 388-93.

2. Hedrick L. Endometrial cancer. In: Vogelstein B, Kinzler KW, editors. The genetic basis of human cancer. New York: McGraw-Hill; 1998. p. 621-9.

3. Kinzler KW, Vogelstein B. Colorectal tumors. In: Vogelstein B, Kinzler KW, editors. The genetic basis of human cancer. New York: McGraw-Hill; 1998. p. 565-87.

4. Sparks AB, Morin PJ, Vogelstein B, Kinzler KW. Mutational analysis of the APC/ $\beta$-catenin/Tcf pathway in colorectal cancer. Cancer Res 1998;58:1130-4.

5. Young CS, Kitamura M, Hardy S, Kitajewski J. Wnt-1 induces growth, cytosolic $\beta$-catenin, and Tcf/Lef transcriptional activation in rat-1 fibroblasts. Mol Cell Biol 1998;18:2474-85.

6. Shimizu H, Julius MA, Giarre M, Zheng Z, Brown AMC, Kitajewski J. Transformation by Wnt family proteins correlates with regulation of $\beta$-catenin. Cell Growth Differ 1997; 8:1349-58.

7. Korinek V, Barker N, Morin PJ, van Wichen D, de Weger R, Kinzler KW, et al. Constitutive transcriptional activation by a beta-catenin-Tcf complex in APC-/- colon carcinoma. Science 1997;275:1784-7.

8. He TC, Sparks AB, Rago C, Hermeking H, Zawel L, da Costa LT, et al. Identification of $c-M Y C$ as a target of the APC pathway. Science 1998;281:1509-12.

9. Tetsu O, McCormick F. $\beta$-catenin regulates expression of cyclin D1 in colon carcinoma cells. Nature 1999;398:422-6.

10. Ilyas M, Tomlinson IP. The interactions of APC, E-cadherin and $\beta$-catenin in tumour development and progression. J Pathol 1997;182:128-37.

11. Polakis P. The oncogenic activation of $\beta$-catenin [review]. Curr Opin Genet Dev 1999;9:15-21.
12. Pennisi E. How a growth control path takes a wrong turn to cancer. Science 1998;281:1438-41.

13. Miyoshi Y, Nagase H, Ando H, Horii A, Ichii S, Nakatsuru S, et al. Somatic mutations of the $A P C$ gene in colorectal tumors: mutation cluster region in the $A P C$ gene. Hum Mol Genet 1992;1:229-33.

14. Fukuchi T, Sakamoto S, Tsuda H, Maruyama K, Nozawa S, Hirohashi S. $\beta$-catenin mutation in carcinoma of the uterine endometrium. Cancer Res 1998;58:3526-8.

15. Kobayashi K, Sagae S, Nishioka Y, Tokino T, Kudo R. Mutations of the $\beta$-catenin gene in endometrial carcinomas. Jpn J Cancer Res 1999;90:55-9.

16. Palacios J, Gamallo C. Mutations in the $\beta$-catenin gene ( $C T$ NNB1) in endometrioid ovarian carcinomas. Cancer Res 1998;58:1344-7.

17. Fearon ER, Hamilton SR, Vogelstein B. Clonal analysis of human colorectal tumors. Science 1987;238:193-7.

18. Katabuchi H, Lambers AR, Ronnett BM, Blazes M, Leach FS, Cho KR, et al. Mutations in DNA mismatch repair genes are not responsible for microsatellite instability in most sporadic endometrial carcinomas. Cancer Res 1995; 55:5556-60.

19. Van der Luijt R, Khan PM, Vasen H, van Leeuwen C, Tops C, Roest $\mathrm{P}$, et al. Rapid detection of translation-terminating mutations at the adenomatous polyposis coli ( $A P C$ ) gene by direct protein truncation test. Genomics 1994;20:1-4.

20. Tashiro H, Blazes MS, Wu R, Cho KR, Bose S, Wang SI, et al. Mutations in PTEN are frequent in endometrial carcinoma, but rare in other common gynecological malignancies. Cancer Res 1997;57:3935-40.

21. Burks RT, Kessis TD, Cho KR, Hedrick L. Microsatellite instability in endometrial carcinoma. Oncogene 1994;9:1163-6.

22. Esteller M, Levine R, Baylin SB, Ellenson LH, Herman JG. $h M L H 1$ promoter hypermethylation is associated with the microsatellite instability phenotype in sporadic endometrial carcinoma. Oncogene 1998;16:2413-7.

23. Ilyas M, Tomlinson IP, Rowan A, Pignatelli M, Bodmer WF. $\beta$-catenin mutations in cell lines established from human colorectal cancers. Proc Nat Acad Sci U S A 1997;94:10330-4.

24. Rubinfeld B, Robbins P, El-Gamil M, Albert I, Porfiri E, Polakis P. Stabilization of $\beta$-catenin by genetic defects in melanoma cell lines. Science 1997;275:1790-2.

25. Zurawel RH, Chiappa SA, Allen C, Raffel C. Sporadic medulloblastomas contain oncogenic $\beta$-catenin mutations. Cancer Res 1998;58:896-9.

26. Voeller HJ, Truica CI, Gelmann EP. $\beta$-catenin mutations in human prostate cancer. Cancer Res 1998;58:2520-3.

27. Kawanishi J, Kato J, Sasaki K, Fujii S, Watanabe N, Niitsu Y, Loss of E-cadherin-dependent cell-cell adhesion due to mutation of the $\beta$-catenin gene in a human cancer cell line, HSC-39. Mol Cell Biol 1995;15:1175-81.

28. Miyoshi Y, Iwao K, Nagasawa Y, Aihara T, Sasaki Y, Imaoka S, et al. Activation of the $\beta$-catenin gene in primary hepatocellular carcinomas by somatic alterations involving exon 3 . Cancer Res;58:2524-7.

29. De La Coste A, Romagnolo B, Billuart P, Renard CA, Buendia MA, Soubrane O, et al. Somatic mutations of the $\beta$-catenin gene are frequent in mouse and human hepatocellular carcinomas. Proc Natl Acad Sci U S A 1998;95:8847-51.

30. Sato S, Ito K, Ozawa N, Yajima A, Sasano H. Expression of c-myc, epidermal growth factor receptor and c-erbB-2 in human endometrial carcinoma and cervical adenocarcinoma. Tohoku J Exp Med 1991;165:137-45.

31. Bai MK, Costopoulos JS, Christoforidou BP, Papadimitriou CS. Immunohistochemical detection of the $c$-myc oncogene product in normal, hyperplastic and carcinomatous endometrium. Oncology 1994;51:314-9.

32. Yokoyama Y, Sagara M, Sato S, Saito Y. Value of glutathione S-transferase pi and the oncogene products c-Jun, c-Fos, 
c-H-Ras, and c-Myc as a prognostic indicator in endometrial carcinomas. Gynecol Oncol 1998;68:280-7.

33. Nikaido T, Li SF, Shiozawa T, Fujii S. Coabnormal expression of cyclin D1 and p53 protein in human uterine endometrial carcinomas. Cancer 1996;78:1248-53.

34. Ito K, Sasano H, Yoshida Y, Sato S, Yajima A. Immunohistochemical study of cyclins D and E and cyclin dependent kinase (cdk) 2 and 4 in human endometrial carcinoma. Anticancer Res 1998;18:1661-4.

35. Prall OWJ, Sarcevic B, Musgrove EA, Watts CKW, Sutherland RL. Estrogen-induced activation of Cdk4 and Cdk2 during G1-S phase progression is accompanied by in- creased cyclin D1 expression and decreased cyclindependent kinase inhibitor association with cyclin E-Cdk2. J Biol Chem 1997;272:10882-94.

36. Altucci L, Addeo R, Cicatiello L, Dauvois S, Parker MG, Truss M, et al. 17 beta-Estradiol induces cyclin D1 gene transcription, p36D1-p34cdk4 complex activation and p105Rb phosphorylation during mitogenic stimulation of G(1)-arrested human breast cancer cells. Oncogene 1996;12:2315-24.

37. Prall OW, Rogan EM, Musgrove EA, Watts CK, Sutherland RL. c-Myc or cyclin D1 mimics estrogen effects on cyclin E-Cdk2 activation and cell cycle reentry. Mol Cell Biol 1998;18:4499508.

\section{Book Review}

lozzo RV, editor: Proteoglycans: Structure, Biology, and Molecular Interactions, 422 pp, New York, Marcel Dekker, Inc., 2000 (\$185).

Even current pathology literature abounds with unfortunate references to mucosubstances or to ground substance. Decades ago that was, perhaps, a defensible way to avoid immersion into a complex topic fraught with unknowns and confusion. The combination of advances in cell and molecular biology has removed the veil of confusion that covered those molecules containing complex carbohydrates (mucosubstances), making proteoglycans and glycosaminoglycans as amenable to study as proteins or any other class of biologic molecules. This first-rate volume does a commendable job in summarizing, in a clear, lucid, and understandable manner, the current knowledge in the field of proteoglycans.

The editor and the 31 authors of this excellent volume deserve congratulations. The 15 book chapters cover all major proteoglycans with clear and up-to-date information on their chemical structure, biosynthesis, catabolism, interactions with the extracellular matrix, cell membranes, cytokines, and the myriad of biologic functions possessed by these fascinating molecules. There are abundant diagrams that help clarify points and solidify information. The only criticism, and it is a minor one, is the lack of a short introduction clarifying the nomenclature. Initially proteoglycans were named by their constituent glycosaminoglycan chains: thus, chondroitin sulfate, heparan sulfate, etc. Later, it was realized that similar glycosaminoglycan chains could be attached to different proteins, and a qualification was introduced: basement membrane heparan sulfate, cell membrane heparan sulfate. After the isolation of the genes coding for the different core proteins, the excellent decision was made to name the proteoglycans according to the gene product: thus, perlecan, syndecan, etc. To those not following the literature on a regular basis, the nomenclature may introduce some difficulty. Nevertheless, this is a minor point and after reading a few chapters the problems disappear. This book can be enthusiastically recommended, not only to those interested in proteoglycans, but also to all concerned with the extracellular matrix and cell biology. In particular it would be helpful to pathologists and may, perhaps, help to stamp out the old term mucosubstances.

\section{Antonio Martinez \\ University of Tennessee School of Medicine Memphis, Tennessee}

